\title{
PARAMETERS AFFECTING THE PERFORMANCE OF THE C-CLASS WINGSAIL
}

\author{
S. R. Turnock, Ship Science, University of Southampton, UK
}

I. M. Cambell, Wolfson Unit Marine Technology and Industrial Aerodynamics, University of Southampton. UK

M. Magherini, Ship Science, University of Southampton, UK

\section{SUMMARY}

Wing sails offer a different design challenge to those of more conventional soft sail rigs. This study was undertaken in order to assess which parameters influence wingsail performance of C-Class catamarans, and to what extent, the results from the wind tunnel can be applied in the design developments of future wingsails. A combined wing sail and $\mathrm{C}$ - class catamaran was tested in the low-speed section of the 7' x 5' wind tunnel at the University of Southampton. Testing assessed the appropriate settings for the movable element of the multiple-element wing sail as well as heeling angle, trampoline porosity, spanwise camber distribution and gap at the foot of the wingsail. Both upwind and downwind conditions were considered through measurement of driving force, heeling force, lift and drag coefficients. The results demonstrate that low heel angles improve overall performance and that the gap underneath the wingsail foot adversely affects the generation of lift by the sail. An airfoil shaped trampoline is suggested in order to benefit both a reduced gap and a better control over the heel. For heavy wind condition, negative twist at the tip of the wingsail allows higher boat speeds.

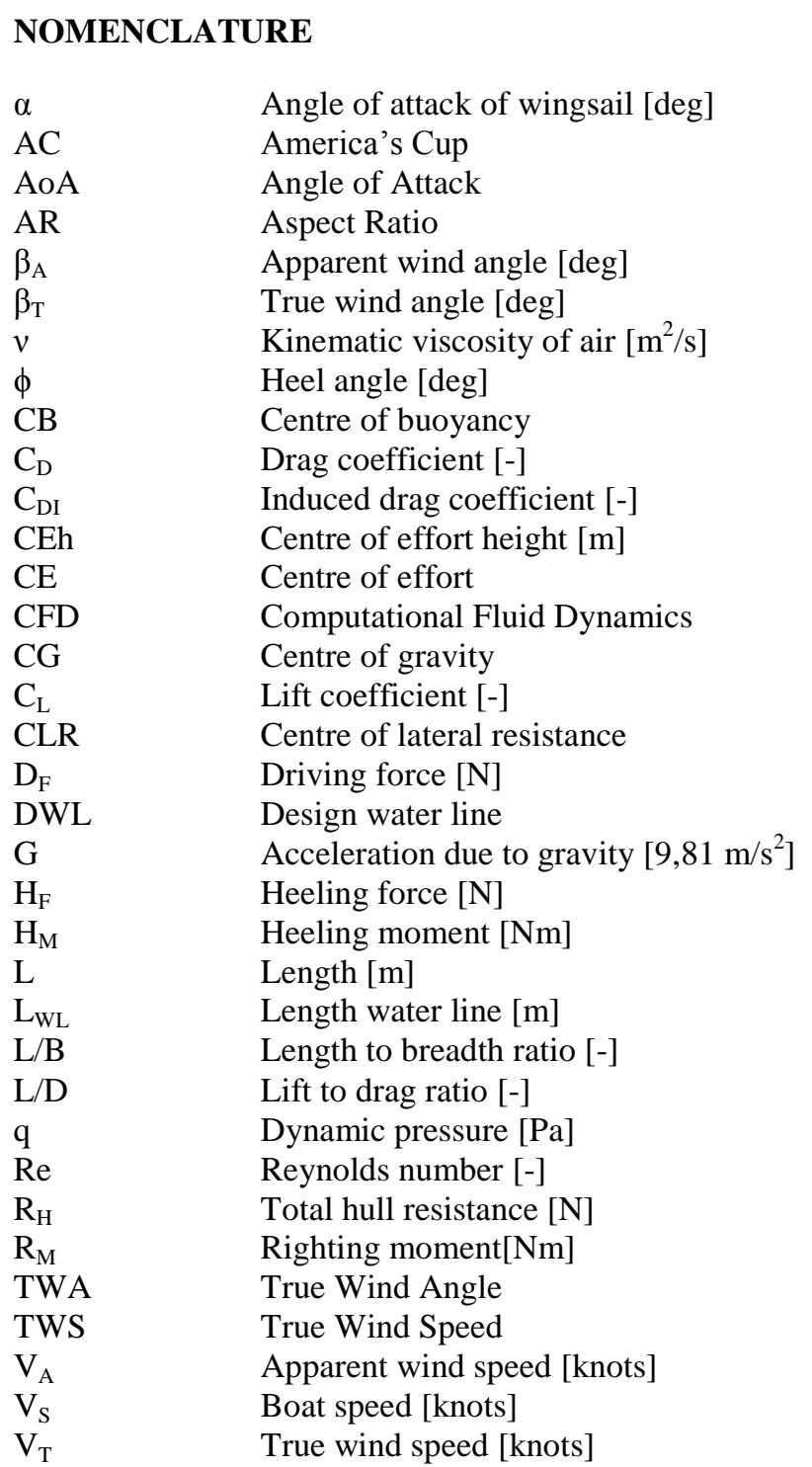

$\begin{array}{ll}\text { VMG } & \text { Velocity Made Good } \\ \text { VPP } & \text { Velocity Prediction Programme } \\ \mathrm{Y}_{\mathrm{M}} & \text { Yawl moment }[\mathrm{Nm}]\end{array}$

\section{INTRODUCTION}

The C-Class catamarans are a sailing class competing in the Little America's Cup (LAC), an international match racing event with the winner of the eliminations series competing in the final race with the defender of the cup. From a research perspective the most interesting element characterizing a C-Class catamaran is their sail propulsion system: a symmetrical rigid wingsail that allows the catamarans to reach velocities $50 \%$ higher than the true wind velocity in upwind sailing, and more than double downwind.

The interest in the class, after several years of relative obscurity, has rapidly grown again in recent times due to the new format of the America's Cup: the trophy wascompeted for in the AC72, 22m long catamarans powered by $40 \mathrm{~m}$ high wingsails. In order to allow teams to develop experience of wingsails, the AC45 $(\mathrm{L}=13,45 \mathrm{~m})$ has been designed as an essential step toward the AC72. The AC45 regattas are held in different venues around the world: both fleet and match racing are part of each event, full live coverage of the events are guaranteed by cameras on board bringing the audience inside the sailing action.

It is worth noting that there is revived interest in wind assisted ship propulsion [1] [2]. Alternative types of sail assistance devices were compared and it was concluded that kites were particularly attractive. However, the operational issues associated with their safe operation may favour fixed structures which with suitable control for optimum drive force generation can provide potential 
energy savings. The technologies developed originally as part of the LAC may aid the future design of such systems.

The aim of the study is to consider how various design parameters influence the performance of a scaled C-Class catamaran wind tunnel model and thus examine possible design options for future catamarans powered by wingsails.

\section{SOFT SAILS vs. WINGSAILS}

As the sail area of a C-Class catamaran is fixed, from a designer point of view the key factor is to maximize the power achievable from the 300 square feet $\left(27.87 \mathrm{~m}^{2}\right)$ of wing sail area allowed across a range of possible wind speeds. Figure 1 shows a typical $\mathrm{C}$ class catamaran in the upwind sailing condition.

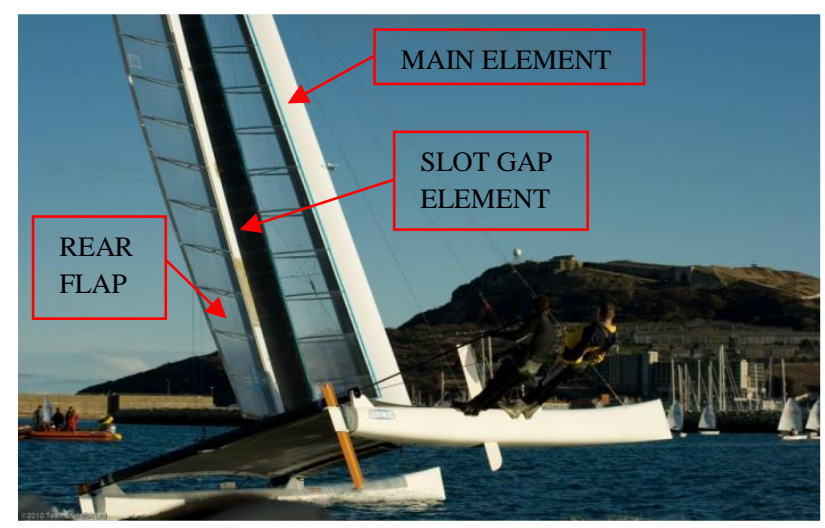

Figure 1: C-Class Catamaran flying windward hull.

A wingsail has some features in common with aircraft wing design with its use of multiple elements such as flaps and slots. As a result of this it can develop higher lift coefficients than conventional sail rigs [3]. The use of stiff components will increase the predictability of the achieved sail shape under given wind conditions, although it can be argued that a fixed geometry reduces the ability of the sailor to more precisely tune their sail for given wind conditions. High-lift devices typically use either slots or flaps to modify the flow regime around the sail section. The slot channelling flow from the high pressure to the low pressure side of the sail and the flap altering the effective camber. The multi-element wingsail adopted in C-Class combines the slot and a shaped rear flap. The flow through the slot ensures the flow over the leading edge of the flap remains attached as well as generating higher sideforce. The effects are:

\footnotetext{
- $\quad$ increase in maximum achieveable $\mathrm{C}_{\mathrm{L}}$,

- delay in stall angle,

- benefits in performance in terms of better boundary layer control, and

- $\quad$ increased control of the camber in order to adjust the angle of attach (AoA) at different mast's heights for the local apparent wind angle $\left(\beta_{\mathrm{A}}\right)$.
}

In order to generate the maximum achievable $\mathrm{C}_{\mathrm{L}}$, the entire sail should be uniformly loaded to obtain the semielliptic load distribution: soft sails' tip tends to be overloaded whereas the bottom can never be fully loaded. The physical reason for such behaviour is the nature of the wind driving a yacht: a twisted flow. As a consequence, the top is stalling before the bottom of the sail preventing the achievement of high average lift coefficients. Differentially, the control system of a wingsail allows twisting the sections at different heights, in order to offer always the optimum $\alpha$ to the twisted $\beta_{\mathrm{A}}$.

\section{C-CLASS WINGSAIL DESIGN CONDITION}

The WinDesign [4] Velocity Prediction Program (VPP) was used to estimate the general sailing parameters related to boat speed $\mathrm{V}_{\mathrm{S}}$, apparent wind speed $\mathrm{V}_{\mathrm{A}}$, and apparent wind angle $\beta_{\mathrm{A}}$, for a range of wind speeds of a $\mathrm{C}$ class catamaran. Due to the lack of specific $\mathrm{C}_{\mathrm{L}}$ and $\mathrm{C}_{\mathrm{D}}$ values for a wingsail, for starting the design process using the VPP it has been assumed that a wingsail typically generates twiced the lift coefficient of a normal soft sail [5] and hence the sail area was doubled in the input for the VPP:

$C_{L \text { wingsail }} \cong 2 C_{L \text { soft sail }}=\frac{L_{\text {soft sail }}}{\rho V^{2} A_{\text {soft sail }}}$.

The demihull of a typical C -Class "Team Invictus" is used for the hydrodynamic modelling. Catamarans assume two equilibrium states: flying and non-flying condition. The VPP is operating in three different "configurations": the boundaries between these set up are defined by the user, defining:

1. the break angle $=$ heel angle at which the windward hull is clear of the water,

2. the fly-angle = mean heel angle at which the catamaran will sail while flying the weather hull.

The maximum heel angle considered for the predictions is the fly-angle at which the crew is at their maximum righting moment. For a C-Class catamaran, a crew of $180 \mathrm{~kg}$ in total and a fly-angle of 10 degrees were considered to be realistic. The multidimensional NewtonRaphson iterative method is used by the solution algorithm to generate the results shown as a velocity polar diagram in Figure 2. The angles plotted in the diagrams are true wind angles [degrees]; the polar curves represent estimated boat speeds [knots] at different true wind speeds. In addition to that, the dots in the polar diagram specify at which heading the best VMG for upwind and downwind sailing is achieved.

The global range of $\beta_{\mathrm{A}}$ (Table 1) at which the wingsail will operate is estimated by the VPP to be between 20 and 60 degrees from the $\beta_{\mathrm{T}}$. In other words, these catamarans are able to sail so fast that they can keep the apparent wind always to the front. 


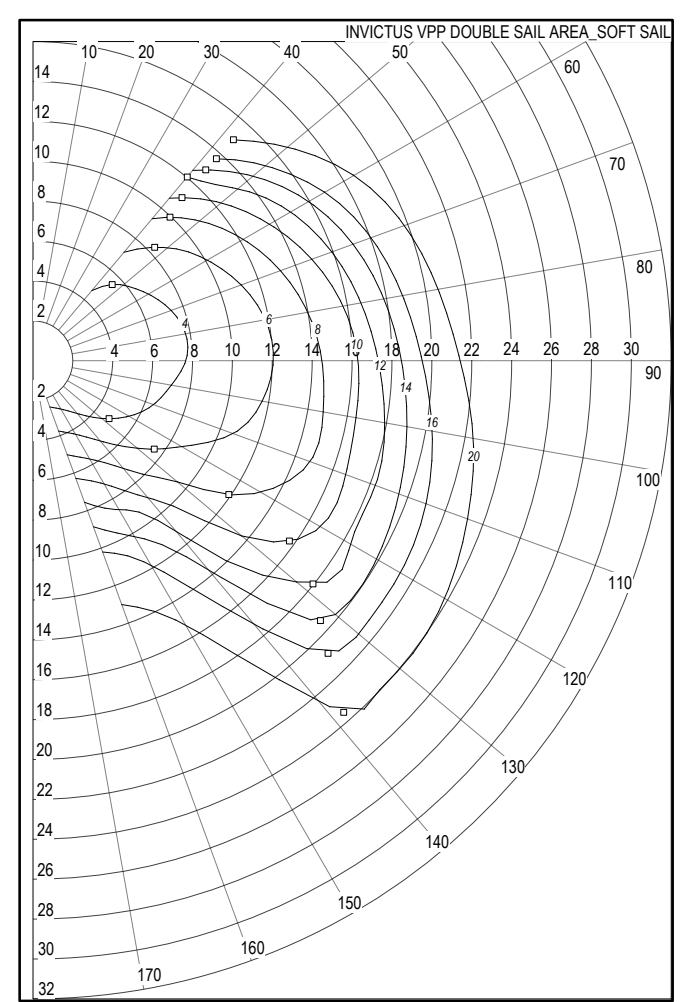

Figure 2: Invictus VPP using double soft sail area.

Table 1:Best $\beta_{\mathrm{A}}, \beta_{\mathrm{T}}$ and VMG for Invictus VPP.

\begin{tabular}{|c|c|c|c|c|c|c|}
\hline \multirow{2}{*}{$\begin{array}{c}\mathbf{V}_{\mathbf{T}} \\
{[\mathbf{k n o t s}]}\end{array}$} & \multicolumn{2}{|c|}{$\boldsymbol{\beta}_{\mathbf{A}}[\mathbf{d e g}]$} & \multicolumn{2}{c|}{$\boldsymbol{\beta}_{\mathbf{T}}[\mathbf{d e g}]$} & \multicolumn{2}{c|}{ VMG [knots] } \\
\cline { 2 - 7 } & $\mathbf{U p}$ & $\mathbf{D w}$ & $\mathbf{U p}$ & $\mathbf{D w}$ & $\mathbf{U p}$ & $\mathbf{D w}$ \\
\hline 4 & 18,6 & 51,7 & 46,2 & 127,3 & 3,81 & 2,9 \\
\hline 6 & 18,8 & 49 & 47 & 126,1 & 5,69 & 4,43 \\
\hline 8 & 18,7 & 40,1 & 43,7 & 124,3 & 7,19 & 6,71 \\
\hline 10 & 19,5 & 37,7 & 42,4 & 125,1 & 8,18 & 9,04 \\
\hline 12 & - & 40 & - & 128,6 & 8,93 & 11,19 \\
\hline 14 & 21,4 & 43,9 & 42,2 & 132,1 & 9,57 & 13,03 \\
\hline 16 & 22,2 & 47,7 & 42,2 & 134,8 & 10,13 & 14,67 \\
\hline 20 & 23,7 & 54,7 & 42,2 & 138,5 & 11,08 & 17,63 \\
\hline
\end{tabular}

Interestingly, the $\beta_{\mathrm{A}}$ presents a non-monotonic behaviour with increasing $\mathrm{V}_{\mathrm{T}}$ : instead it follows the trend of the $\beta_{\mathrm{T}}$, which at 10 knots of $V_{T}$, the $\beta_{\mathrm{T}}$ starts increasing with increases in true wind speed. This result is also confirmed by proven technique used to sail downwind a C-Class catamaran [3].

\section{$3.1 \quad$ UPWIND REQUIREMENTS}

The upwind requirement for a yacht is that the ratio $\mathrm{D}_{\mathrm{F}} / \mathrm{H}_{\mathrm{M}}$ is maximised. Driving force and heeling forces are given respectively as:

$D_{F}=L \sin \beta_{A}-D \cos \beta_{A}$,

$H_{F}=\left(L \cos \beta_{A}+D \sin \beta_{A}\right) \cos \phi$,
$H_{M}=H_{F} a$,

where $a$ is the distance between the CLRand the CE of the sailplan. In a steady sailing condition, the heeling moment generated by the sailplan has to be balanced by the righting moment produced by the hull and its crew:

$H_{M}=R_{M c a t}=W_{C A T} l_{1} \cos \Phi+W_{C R E W} l_{2} \cos \Phi ;$

where, $\mathrm{W}_{\mathrm{CAT}}$ and $\mathrm{l}_{1} \cos (\phi)$ are respectively the weight of the catamaran and the distance between $\mathrm{CB}$ and $\mathrm{CG}$ in which the total weight is applied. Identical meaning has $\mathrm{W}_{\text {CREW }}$ and $\mathrm{l}_{2} \cos (\phi)$, for the crew's weight. Last equation relates $\phi$ with the $\mathrm{H}_{\mathrm{M}}$ : being a cosine function, an increase in the heel angle will decrease the righting moment. Therefore, the maximum righting moment is achieved when the heel angle is at a minimum. A decrease in drag will cause a decrease in the $\mathrm{H}_{\mathrm{F}}$ and an increase in the $\mathrm{D}_{\mathrm{F}}$. Lift and drag for a sail of area A are defined as:

$$
\begin{aligned}
& L=\frac{1}{2} \rho A V_{A}^{2} C_{L} ; \\
& D=\frac{1}{2} \rho A V_{A}^{2} C_{D} .
\end{aligned}
$$

The drag coefficient is defined as:

$C_{D}=C_{D 0}+C_{D I}$

where, $\mathrm{C}_{\mathrm{D} 0}$ is the formdrag due to the skin friction and turbulence of the air following over the sail and its supporting structure with its associated flow separations; $\mathrm{C}_{\mathrm{DI}}$, the induced drag, is a function of the vertical distribution of aerodynamic loading and it is defined:

$C_{D I}=\frac{C_{L}^{2}}{\pi A R}$

Recent studies [6] implemented an additional pressure drag coefficient due to separation, likely to occur in high lift situation. Nevertheless, this study employs the classical potential flow model (eq. 8). The induced drag is the largest drag component. For reducing $\mathrm{C}_{\mathrm{DI}}$, a high aspect ratio airfoil is required; nevertheless, a tall rig will have a higher vertical centre of effort CEh increasing the heeling moment and ending in penalizing the $\mathrm{D}_{\mathrm{F}}$. To reduce the $\mathrm{CEh}$, a negative lift distribution can be used at the tip of the wingsail which has been proved to obtain the best $\mathrm{D}_{\mathrm{F}} / \mathrm{H}_{\mathrm{M}}$ for strong winds condition [7].

\subsection{DOWNWIND REQUIREMENTS}

High speed sailing catamaran never sail straight downwind in order to achieve the maximum $\mathrm{V}_{\mathrm{MG}}$, for the following reason:

- when $\mathrm{V}_{\mathrm{S}}$ is increasing (accelerating), consequently $\mathrm{V}_{\mathrm{A}}$ will inevitably decrease (course in the direction of the wind),

The heeling moment of a catamaran is: 
- $\quad$ since $D_{F}=f\left(V_{A}^{2}\right)$ and $R_{H}=f\left(V_{S}^{3}\right)$, it becomes difficult to obtain any significant gains in sailing straight to the wind.

C-Class catamarans tack downwind jibing through approximately 90 degrees jibe to jibe (so called technique "iceboating" after the similar technique used when sailing on ice) [3]. At these angles and with the speeds these catamarans can reach, the $\mathrm{V}_{\mathrm{A}}$ is moved well forward of the beam and they manage to fly a hull while close reaching in the accelerated $\mathrm{V}_{\mathrm{A}}$. The higher $\mathrm{V}_{\mathrm{S}}$ is, the higher $\mathrm{V}_{\mathrm{A}}$ becomes, and the more power is obtained. Sail drag is of secondary importance, whereas the lift force generating the thrust in the direction of the course is of prime importance. Therefore, the downwind requirement is to design a wingsail than can generate a $\mathrm{C}_{\mathrm{L} \text { MAX }}$ over the entire span of the wing. A high level of camber is requested in order to adjust the wing's AoA to the twisted flow acting on it; with flap angle of about 3035 degrees, wingsails can produce their best performances.

\section{WIND TUNNEL TESTING}

In order to assess the complex interaction of the differential twisting of a wingsail with its trampoline, a scaled model (Table 2) was tested in the large crosssection straight flow low speed section of the University of Southampton 7'x5' closed return wind tunnel.

\subsection{WIND TUNNEL MODEL-DESIGN}

The model's requirements considered crucial were:

- possibility of changing the heeling angle in the tests,

- possibility of controlling the AoA of the wingsail,

- possibility of changing type of trampoline.

Due to time constraints, a wingsail designed in a previous research project was used [5]; therefore, the model also required being able to accommodate the wingsail previously tested. The scaling procedure started from the area of the model wingsail: of GDP 34:

$A_{\text {wingsail }}=0.72 \mathrm{~m}^{2}$.

The area of a C-Class wingsail is:

$A_{\text {wingsail C-Class }}=27.87 \mathrm{~m}^{2}$.

Therefore, the scaling factor is:

$\lambda=\sqrt{\frac{A_{\text {wingasil C-Class }}}{A_{\text {wingsail }}}}=6.22$.

Next, all the dimensions of the full scale catamaran has been scaled according to $\lambda$ :
Table 2: Main wind tunnel model dimensions

\begin{tabular}{|lll|}
\hline Parameters & Full Scale & Model Scale \\
\hline Sail Area [m2] & 27.87 & 0.72 \\
LOA [m] & 7.62 & 1.225 \\
Beam [m] & 4.267 & 0.686 \\
\hline
\end{tabular}

The catamaran structure is composed of aluminium box sections of $31 \times 31 \times 3 \mathrm{~mm}$ (see Figure 3 ). The demihulls are connected together by two aluminium cylinders with a diameter of $30 \mathrm{~mm}$ and $3 \mathrm{~mm}$ of thickness bolted to the square bars. To enable model testing at different heeling angle, a semi-circular aluminium bar is designed to be connected to the dynamometer fittings with holes at every 5 degrees of heel. The axis of rotation of the whole model is the one given by the rotation of the bow fitting around the aluminium bar connected in the forward fitting of the dynamometer.

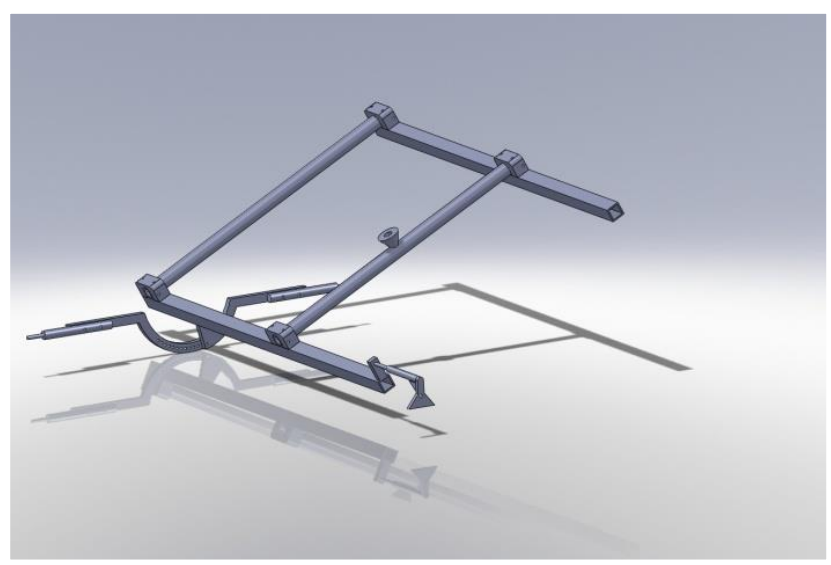

Figure 3: Wind tunnel model internal structure.

To represent the windage resistance, demihulls made by foam scaled from Invictus hull are designed to cover entirely the aluminium structural bars, in order to provide a realistic aerodynamic shape (see figure 4).

A benefit of this model design is its flexibility, it can be reused for different types of boat by redesigning the foam shape covering the aluminium bars. The beams can be removed or changed in dimensions either to test monohulls or catamarans with different width. 


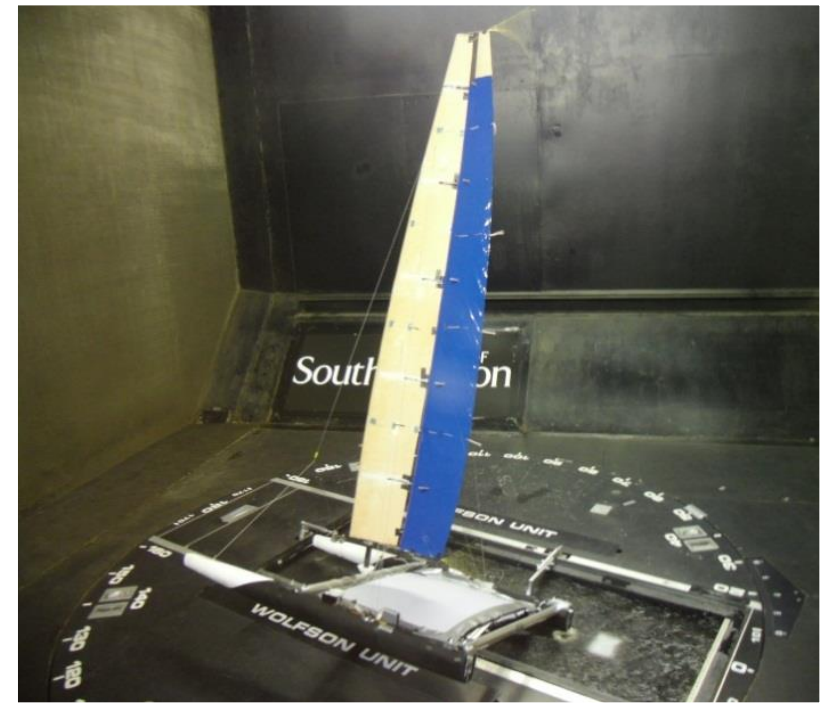

Figure 4-: Wind tunnel model during tests. Flow is left to right.

\subsection{METHODOLOGY OF TESTING}

During the tests, the angle of attack of the foreelement was controlled with an electrical winch (see Figure 5), whereas the second element was manually fixed at a certain angle relatively to the first. In other words, the "global" angle of attack of the wingsail was controlled. For upwind sailing, a flap angle of 10 degrees (angle between the longitudinal axis of the wingsail's fore element and the flap) was estimated to be realistic. For the downwind case, a flap angle of 20 degrees was adopted as constant cambered configurations. For the twisted configurations, the first step was to set the wing at a constant flap angle (respectively 10 or 20 degrees for upwind/downwind $\beta_{\mathrm{A}} \mathrm{s}$ ). This ensured a correct opening of the slot gap between the two elements. For achieving twist on the flap element, an hinge and track system was adopted [8]: shrink wrapping was used around wooden sections of the element to cover the wing.

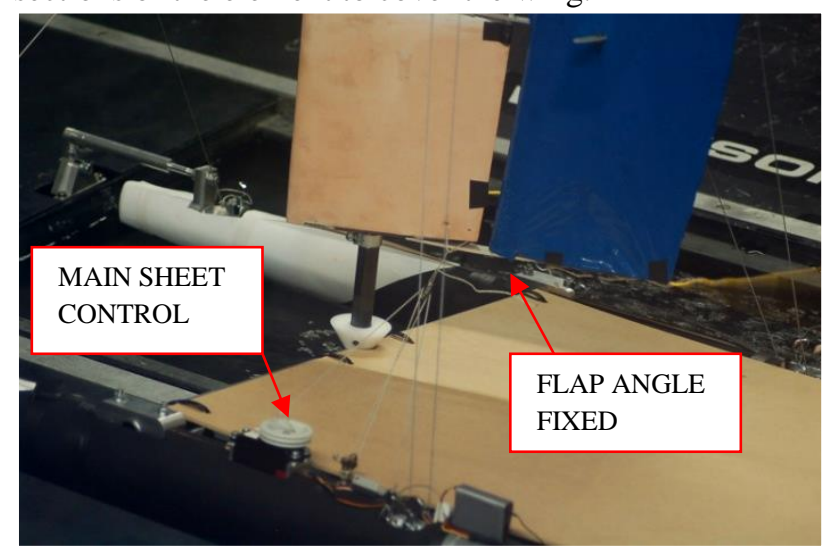

Figure 5: Wind tunnel model control system.

For the sealed gap configuration tested, the mast was shortened by about $100 \mathrm{~mm}$ at the base, and a plastic sheet was applied to seal the wing foot with the solid platform (see Figure 17).
The following testing procedure for the different configurations was adopted:

- $\quad$ Setup of the model: the turntable was fixed at a certain AWA, the model was fixed at given heel angle, the camber distribution was adjusted,

- Dynamometer re-zeroed (function of the acquisition software): due to the drift in the experimental instruments after long runs, the zero has to be reset. The strain gauges are measuring an unsteady signal; therefore, the data are sampled for a period of 10 seconds and then the mean force block values are recorded. In order to recreate the oscillation of the measurements, before re-zeroing a small "kick" was given to the model [9],

- Wind ON: constant dynamic pressure mode operated by the wind tunnel technician,

- Wingsail trimming: due to the friction applied by the lateral shrouds, the wind pressure was not powerful enough to completely sheet out the wing; hence, the wing was left at zero angle of attack and started to be pulled from the zero lift condition; with such a method it was possible to record more data points,

- Data acquisition: using Lasso software, each set of sailing points $\left(\mathrm{D}_{\mathrm{F}}, \mathrm{H}_{\mathrm{F}}, \mathrm{H}_{\mathrm{M}}, \mathrm{Y}_{\mathrm{M}}\right)$ were acquired for different trims. In order to obtain a complete distribution of points in the $C_{D} / C_{L}^{2}$ plot, the wingsail was trimmed in order to acquire at least eight data points for each run before stall is reached,

- Wind OFF: the technician was shutting off the tunnel's fan when the set of data for a particular run was completed (i.e. 8 data points acquired, maximum driving force achieved and stall appeared by looking at the tell tales),

- End zero value: measured forces with the wind completely stopped were acquired in order to apply the end zero corrections (discussed in the next chapter); the same "kick procedure" explained for re-zeroing the dynamometer was employed.

For completing a run, the average time requested is of about 20 minutes. Longer run times should be avoided due to the increase in the internal temperature of tunnel which affects the measurements [10] [11] [12].

Tests without wing for the different configurations have been conducted separately to acquire values for the windage.

\section{W.3 WIND TUNNEL CORRECTIONS}

From the acquisition software Lasso the values for driving force, heeling force and consequently heeling moment and yawing moment were acquired. These raw values need to be corrected. Firstly, the end zero 
correction was employed, using the formula (for instance, for the driving force):

$D_{F}=D_{F \text { raw }}-D_{F \text { end }} \frac{1+R U N \#-S T A R T R U N \#}{\text { FINISH RUN \#-START RUN\#. }} .(11)$

This correction is due to the drift in the dynamometer load cells during a set of runs proved by the presence of residual stresses after every run even after the wind in the tunnel is off. Secondly, the forces need to be transformed from the boat axisset at zero leeway angle on the balance, to tunnel axis. The $\beta_{\mathrm{A}}$ for the heeled condition can be estimated as follows [13]:

$\beta_{\text {A heeled case }}=\tan ^{-1}\left(\tan \beta_{\text {Aupright }} \cos \phi\right)$.

Reversing the above equation and (2) (3), lift and drag coefficients are then calculated as (6) (7) by the forces normalized by the sail area and the dynamic pressure: this procedure is simplifying the analysis because the algorithms adopted by the VPP are working with coefficients in the plane normal to the mast.

Wall boundary and wake blockage corrections were employed [6]:

$C_{D \text { corrected }}=C_{D}+\frac{\delta A_{W} C_{L}^{2}}{C}$,

$\beta_{\text {corrected }}=\beta+\frac{\delta A_{W} C_{L}}{C}$

$\delta$ is the downwash correction for the specific wind tunnel $(=0.09), \mathrm{A}_{\mathrm{W}}$ is the wingsail area, and $\mathrm{C}$ is the tunnel cross section area $(=14,6 \mathrm{~m})$. The same correction routine presented above has been adopted for the "wing only" case (without windage), the only difference consisted in subtracting the windage values (for $\mathrm{D}_{\mathrm{F}}, \mathrm{H}_{\mathrm{F}}, \mathrm{H}_{\mathrm{M}}, \mathrm{Y}_{\mathrm{M}}$ ) from the totalsbefore transforming the forces to tunnelaxis.

\subsection{EXPERIMENTAL UNCERTAINTY}

In order to obtain the same characteristics in terms of flow pattern between full scale and model scale, the Reynolds number has to be the same:

$R e_{\text {full scale }}=\frac{V L}{v}=R e_{\text {model scale }}$,

$v$ is function of the temperature of the air; therefore it will change as the tunnel temperature increases (for instance, after a long run). For this reason, the tests were conducted at constant dynamic pressure mode. Knowing that $q$ is:

$q=\frac{1}{2} \rho_{\text {air }} V_{A}^{2}$ the analysis with lift and drag coefficients can be conducted without issues about air temperature changes. Nevertheless, with the wind speeds used for sailing yachts tests, the same Re as the full scale case can never be achieved.. Screens are fitted to improve flow uniformity which however remains uneven [14].

Four different dynamic heads at different wind speeds have been tested measuring the forces generated at $\beta_{\mathrm{A}}=0$ deg. The result shows a dependency of the measured forces with $\mathrm{Re}$ : on the $\mathrm{x}$ axis, the $\mathrm{Re}$ is calculated using the maximum chord length of the model; on the y axis, the driving force $(\mathrm{Cx})$ and heeling force $(\mathrm{Cy})$ coefficients are obtained by normalizing the forces by the wingsail area and q. The runs were conducted in a short time and an average temperature of $31^{0}$ was used for the kinematic viscosity of the air.

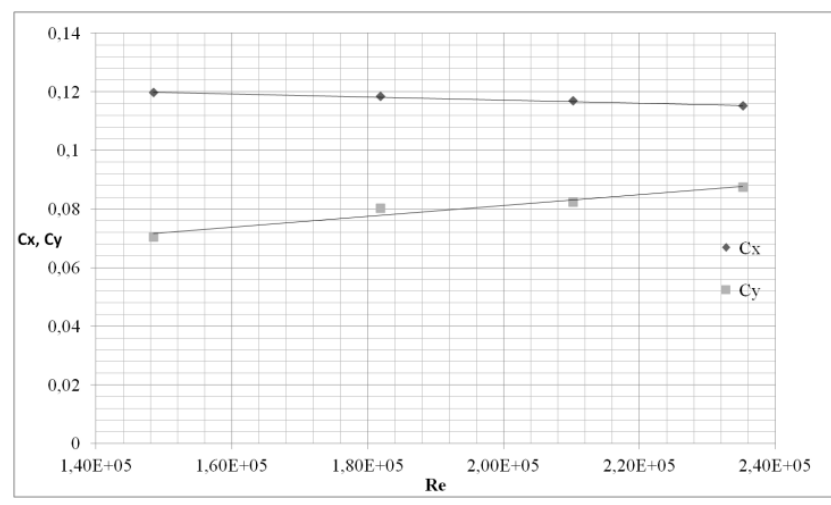

Figure 6: Reynolds number dependency study for driving and heeling forces.

Due to the variety of configurations tested, the main issue encountered was the control of the slot gap between the two elements while the wingsail was cambered.

Moreover, due to the curved trailing edge of the second element, a change in the camber results in an increase in the slot gap. After several attempts, a solution for fixing the flap angle was found: depending by which particular twist was requested, little aluminium bars were applied along the span fixing the hinges relatively to the first element. Consequently, templates made out of cardboard were taken for each different setting at different section heights, in order to control any amount of variation in the camber distribution during a run. The templates guaranteed the possibility of repeating a particular camber distribution after any number of runs with different configurations.

\section{RESULTS AND DISCUSSION}

\subsection{EFFECT OF HEEL}

Tests were conducted for 3 different heel angles: 10, 20, 30 degrees. In Figure 7, $\mathrm{D}_{\mathrm{F}}$ versus $\mathrm{H}_{\mathrm{M}}$ ratio is reported in the upwind case for the net configuration. 
The optimum heel angle was found to be at $\phi=10$ degrees driving forces achieved at same heeling moments are always higher at 10 degrees than for the higher angles.

The reason for that is mainly due to the reduction in the $\beta_{\mathrm{A}}$ with heel,(eq. 12)::

being a cosine function, with an increase in heel $(\phi)$, the AWA in the heeled condition decreases, reducing the driving force generated by the wingsail.

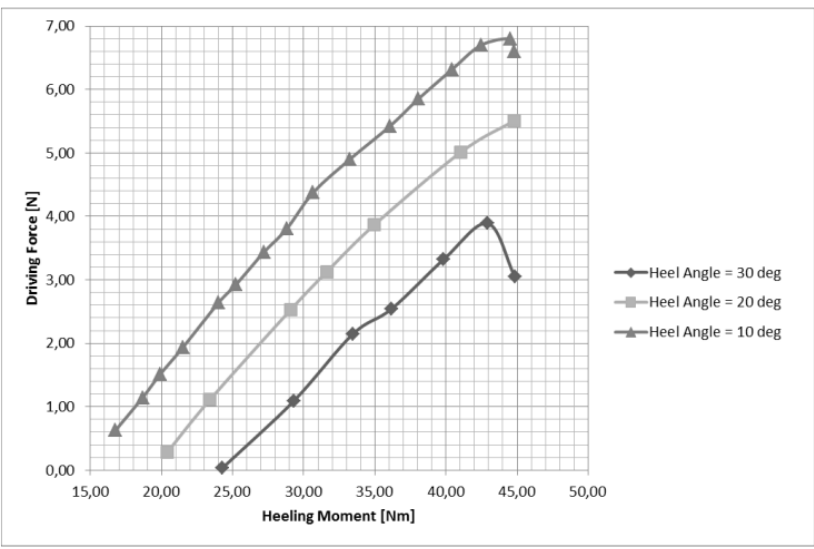

Figure 7: $\beta_{\mathrm{A}}=20 \mathrm{deg}$, net platform, with windage

Other considerations might be undertaken concerning the heel parameter by plotting $C_{D} v{ }^{2} C_{L}^{2}$ (Figure 8 ).

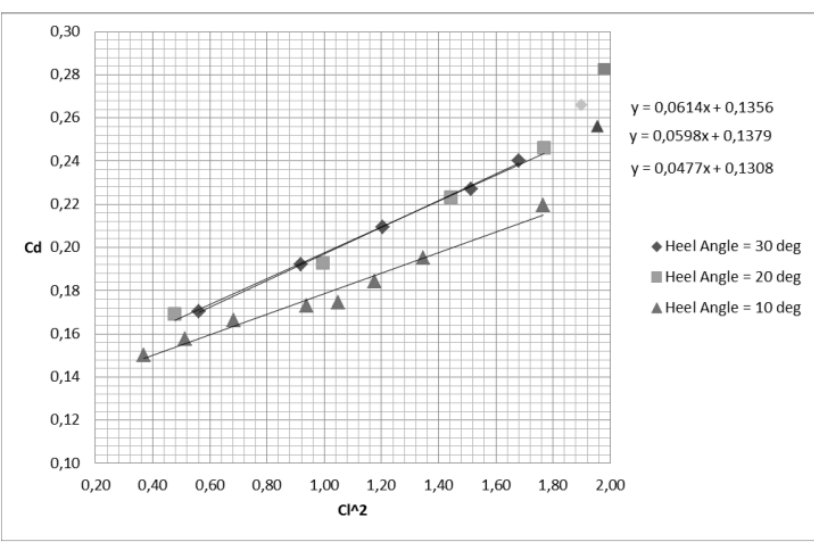

Figure 8: $\beta_{\mathrm{A}}=20 \mathrm{deg}$, no trampoline, with windage

The base drag is lower for $\phi=10 \mathrm{deg}\left(\mathrm{C}_{\mathrm{D} 0}=0.131\right)$. It increases with higher heeling $\left(\mathrm{C}_{\mathrm{D} 0}=0.137\right.$ at $\left.\phi=20 \mathrm{deg}\right)$ : that is due to the smaller projected area of the bare hull in the direction of the wind. After subtracting the windage values, the base drags at different heel are similar, giving consistency in the results [8].

The induce drag increases with the heel angle $\left(\mathrm{C}_{\mathrm{DI}}=0.048\right.$ at $\phi=10 \mathrm{deg}$, to a value of 0.061 at $\phi=30 \mathrm{deg}$ ): the increased gap underneath the wing foot due to heel is influencing the induced drag of the wingsail.
Tests conducted with an $\beta_{\mathrm{A}}=25 \mathrm{deg}$ demonstrated that the negative effect of heeling on the $\mathrm{D}_{\mathrm{F}} / \mathrm{H}_{\mathrm{M}}$ ratio is less sensible. In other words, during a downwind leg in which the maximum thrust requirement will not be limited by the $\mathrm{H}_{\mathrm{M}}$, heeling at more than 10 degrees will not affect negatively the performance as during an upwind leg.

\subsection{EFFECT OF TRAMPOLINE POROSITY}

Three different configurations were tested for the upwind case: a solid platform made by an MDF panel, a net trampoline made out of fabric with a $2 \mathrm{~mm}$ spacing and finally a configuration with neither net or platform. A comparison is made, for a consistent $\beta_{\mathrm{A}}$ of $20 \mathrm{deg}$, the influence of these root geometries on the wing sail drive force with windage for $\phi=30 \mathrm{deg}$ (Fig. 9) and the optimum $\phi=10 \mathrm{deg}$ (Fig. 10). Figure 11 presents their effect on induced drag and Fig 12 removes the effect of windage on drive force.

At the optimum heel angle $\phi=10 \mathrm{deg}$, the trampoline without net is the best performer. At $\phi=30 \mathrm{deg}$ (Figure 9), the solid trampoline generates higher $\mathrm{D}_{\mathrm{F}}$ than the "nonet" platform. Moreover, the platform's differences in driving forces are more marked for the higher heel angle.

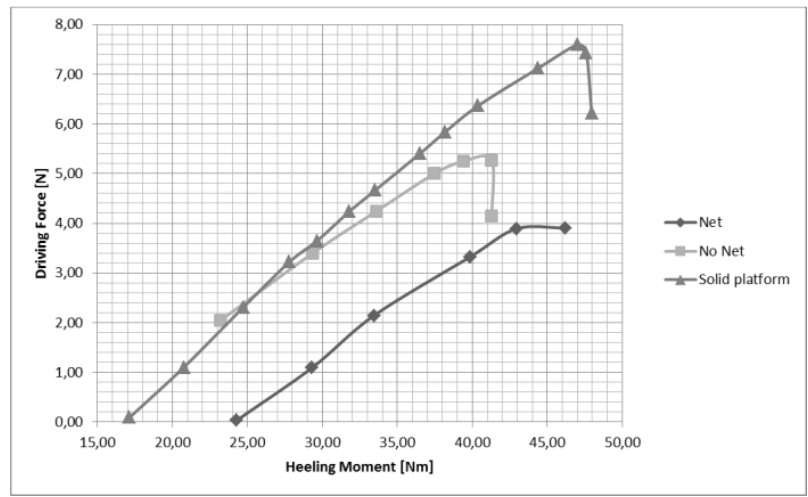

Figure 9: AWA=20deg, $\Phi=30 \mathrm{deg}$, with windage

From the $\mathrm{C}_{\mathrm{D}} / \mathrm{C}_{\mathrm{L}}^{2}$ plots a better understanding of what is presentedabove it is achieved. At $\phi=10 \mathrm{deg}$ (Figure 10), the induced drag of the "no-net" trampoline is smaller $\left(\mathrm{C}_{\mathrm{DI}}=0.051\right)$; it is higher for the solid platform $\left(C_{D I}=0.059\right)$ and the net configuration $\left(C_{D I}=0.054\right)$. The small angle of heel allows the wingsail to operate close to the wind tunnel floor; therefore, the effect of the solid platform is not resulting in any advantage in terms of reducing the gap underneath the wingsail foot. Instead, the solid platform is disturbing the incoming flow at the lower sections of the wing. 


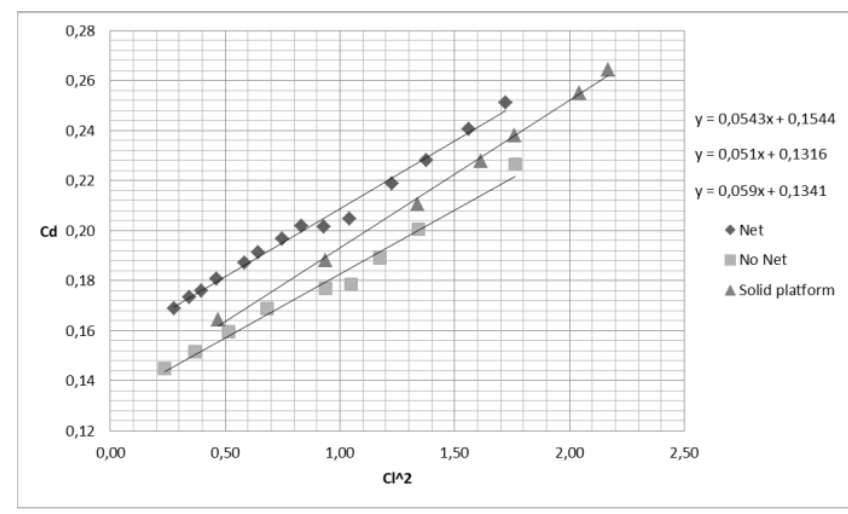

Figure 10: AWA=20deg, $\phi=10 \mathrm{deg}$, with windage

The base drag of the "no-net" trampoline is smaller than the other configurations for every heel angle: this trend is more marked at $\phi=30 \mathrm{deg}$ (Figure 11) at which angle the 'no-net' base drag is $\mathrm{C}_{\mathrm{D} 0}=0.13$, whereas for the solid platform it is $\mathrm{C}_{\mathrm{D} 0}=0.16$. The net platform is generating the highest base drag $\left(C_{D 0}=0.204\right)$. For all heel angles, the net platform is the worst performer: the fabric net deforms like a sail between the demihulls generating parasitic drag without enhancing the lift of the sail.

Interestingly, at $\phi=30 \mathrm{deg}$, the solid platform is presenting the smaller $\mathrm{C}_{\mathrm{DI}}(=0.043)$ compared with the other platforms. This result demonstrates that the solid platform is generating an effective shield effect on the wing foot decreasing the gap underneath it.

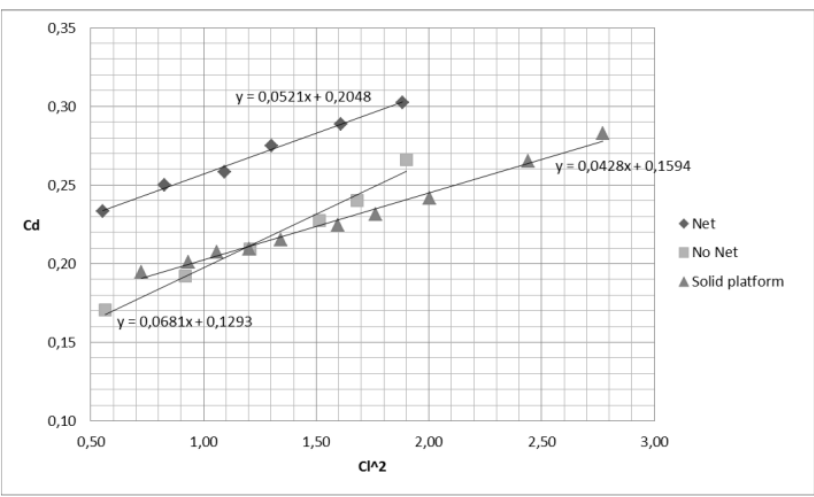

Figure 11: AWA=20deg, $\phi=30 \mathrm{deg}$, with windage

Moreover, by plotting the $\mathrm{D}_{\mathrm{F}}$ vs. $\mathrm{H}_{\mathrm{M}}$ ratio without windage at 30 degrees of heel, another consideration about the solid platform emerges: the catamaran without net is the best option (Figure 12). That implies that the solid platform for high heeling angle is acting as a longitudinal airfoil capable of generating a certain amount of lift and consequently driving force.

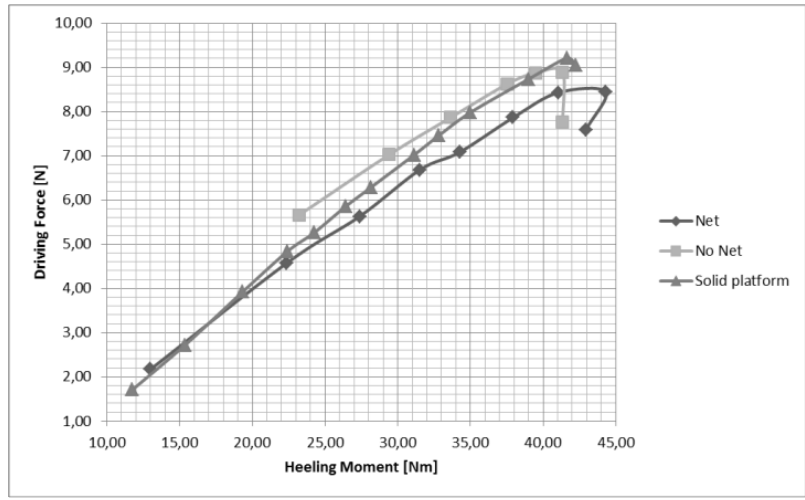

Figure 12: AWA=20deg, $\phi=30 \mathrm{deg}$, without windage

\subsection{EFFECT OF CAMBER DISTRIBUTION}

Different twist profiles have been tested simulating upwind and downwind requirements. The results have been compared with the "constant cambered" configurations: 10 and 20 degrees respectively for upwind and downwind sailing condition. Only the solid platform at $\phi=10 \mathrm{deg}$ has been used for this batch of tests. The wingsail constantly cambered at 20 degrees performed better than the other twisted configurations due to the untwisted flow of the wind tunnel; therefore, results will not be discussed in this paper. However, it is worth noting what influences the sail performance is the relative twist to the on-set wind which is captured in this work.

Table 3 shows the flap angle of two significant twist profiles at different heights: the flap angle is intended asthe angle between the longitudinal axis of the aft element (cambered at 10 degress relatively to the fore one) and the twist imposed with the hinge and track system (Figure13)..

Table 3: Twisted profile settings

\begin{tabular}{|lcc|}
\hline SECTIONS & TWIST A [deg] & TWIST B [deg] \\
\hline tip & -10 & 0 \\
\hline \multirow{3}{*}{ middle } & -5 & 0 \\
& 0 & 5 \\
root & 5 & 10 \\
\hline
\end{tabular}




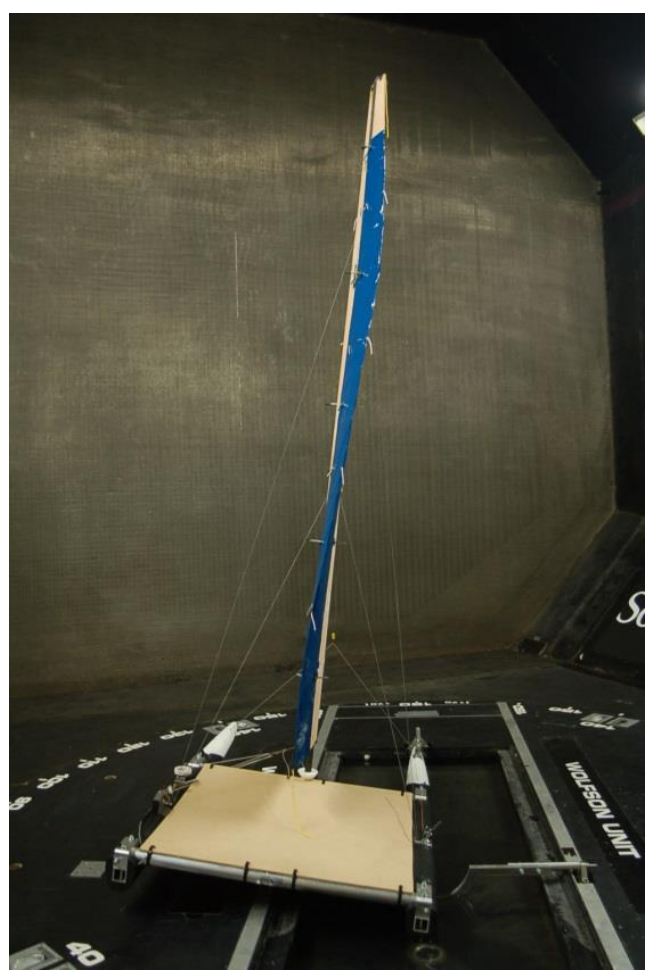

Figure 13: Twisted configuration A.

By analysing the results, the following statements can be made. At small values of $H_{M}$, the $D_{F} v s . H_{M}$ ratio is higher for both twisted configurations " $\mathrm{A}$ " and " $\mathrm{B}$ " compared with the constant flap angle at 10 degrees.

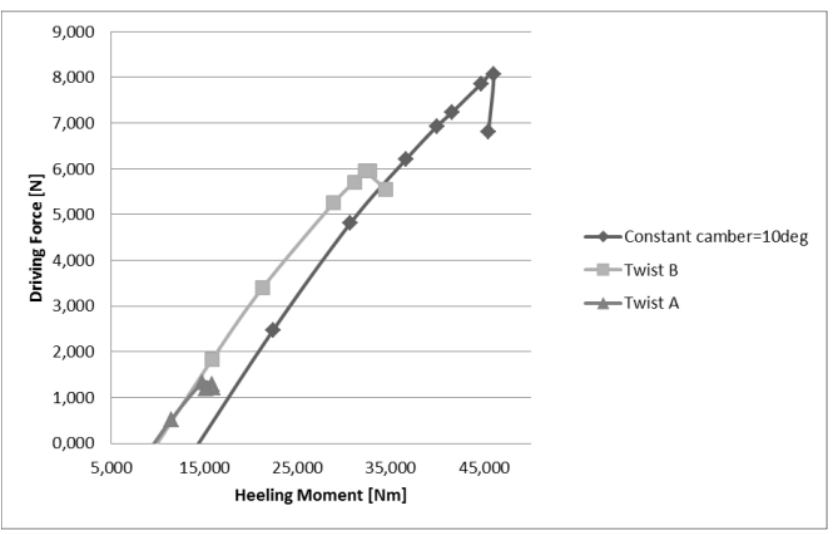

Figure 14: AWA=20deg, $\phi=10 \mathrm{deg}$, with windage

Twist " $A$ " and " $B$ " were tested in order to depower the tip of the wing (particularly in " $A$ " in which a negative spanwise lift distribution at the tip is attempted). The beneficial effect of depowering the top of a sail is in the reduction of the CEh which results in decreased heeling moments. The maximum $\mathrm{D}_{\mathrm{F}}$ achieved by the "constant cambered" wingsail is higher; nevertheless, wind tunnel tests are conducted at same wind speed for both constant and twisted configurations. If the wind speed is increased, the limitation of the maximum righting moment will set a fixed value of heeling moment before capsizing: in such a condition, the twisted configurations will be faster with higher $\mathrm{D}_{\mathrm{F}}$ at given $\mathrm{H}_{\mathrm{M}}$. In other words, even though the constant cambered wing is able to produce higher maximum $\mathrm{D}_{\mathrm{F}}$ overall, in heavy winds the wingsail will need to be depowered more than a twisted configuration for reaching the equilibrium $R_{M}=H_{M}$, resulting in lower driving force. In order to translate this finding to a real sailing situation, a VPP analysis is given in Section 5.The amount of lift and consequently driving force lost by depowering the tip of the wing (no tip vortex observed during the tests) is compansated bythe decrease in CEh.

Figure 15 shows the CEh variations as function of heeling force coefficients for the 3 different configurations: on the $\mathrm{x}$-axis, $\mathrm{Cy}$ is normalized by the wing area; on the $\mathrm{y}$-axis, the CEh is plotted as percentage of the wingsail's height above the waterline.

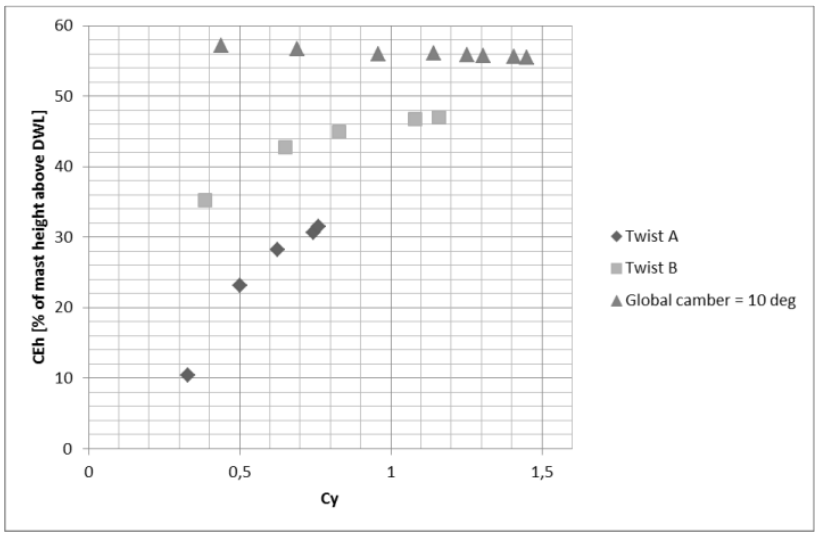

Figure 15: CEh/Cy at AWA=20deg, $\phi=10 \mathrm{deg}$, with windage

\section{4 EFFECT OF THE GAP AT THE WINGSAIL FOOT}

The effect of gap on wingsail performance was investigated using the solid platform as shown in figure 16. The sealed configuration is considered to be beneficial for the upwind requirement of optimizing the efficiency of the rig.

The maximum driving forces achieved by sealed and with gap configurations are similar $\left(\mathrm{D}_{\mathrm{F}}=8 \mathrm{~N}\right)$; comparing the results at fixed $\mathrm{H}_{\mathrm{M}}$, the "sealed gap" is the best performer because it generates higher $\mathrm{D}_{\mathrm{F}}$. The CEh in the sealed case is lower because the rig span was reduced. 


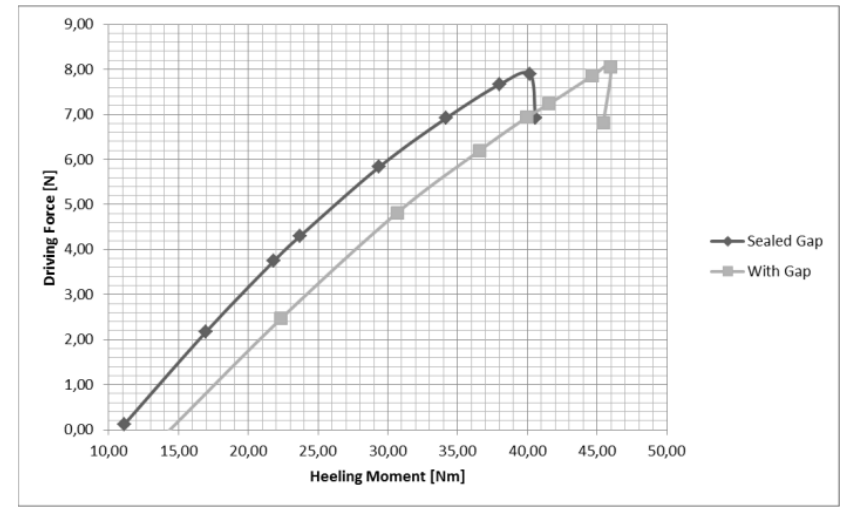

Figure 16: AWA=20deg, $\phi=10 \mathrm{deg}$, with windage

In Figure.17, the induced drag tested in the sealed configuration is higher $\left(\mathrm{C}_{\mathrm{DI}}=0.065\right)$ than the wing with the gap $\left(\mathrm{C}_{\mathrm{DI}}=0.057\right)$. In contrast with the classic lifting line theory, where an elliptical spanwise lift distribution and a sealed gap represents the best windward performances [4], the wind tunnel tests demonstrate that some practical implications have also to be taken into account (sealing platform shape has to be studied in combination with wingsail foot).

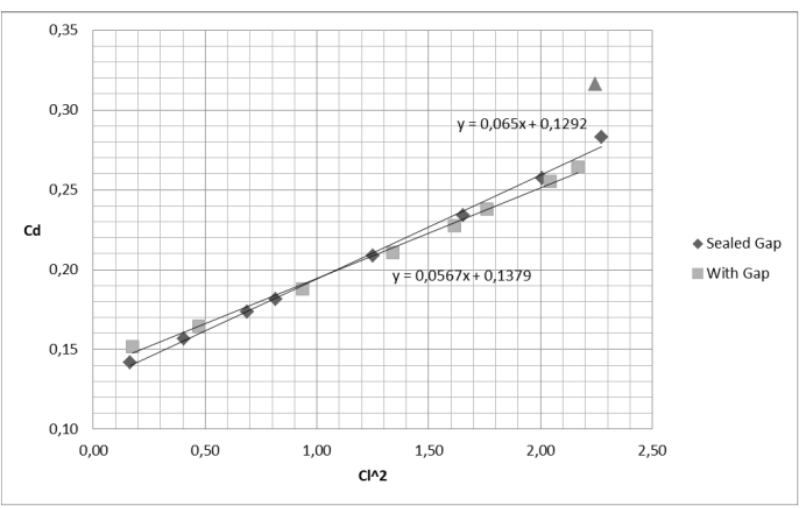

Figure 17: AWA=20deg, $\phi=10 \mathrm{deg}$, with windage

The disturbed flow generated by the solid platform affects the performance of the wingsail's lower sections causing early separation as observed by the tell tales during the tests in Figure 18.

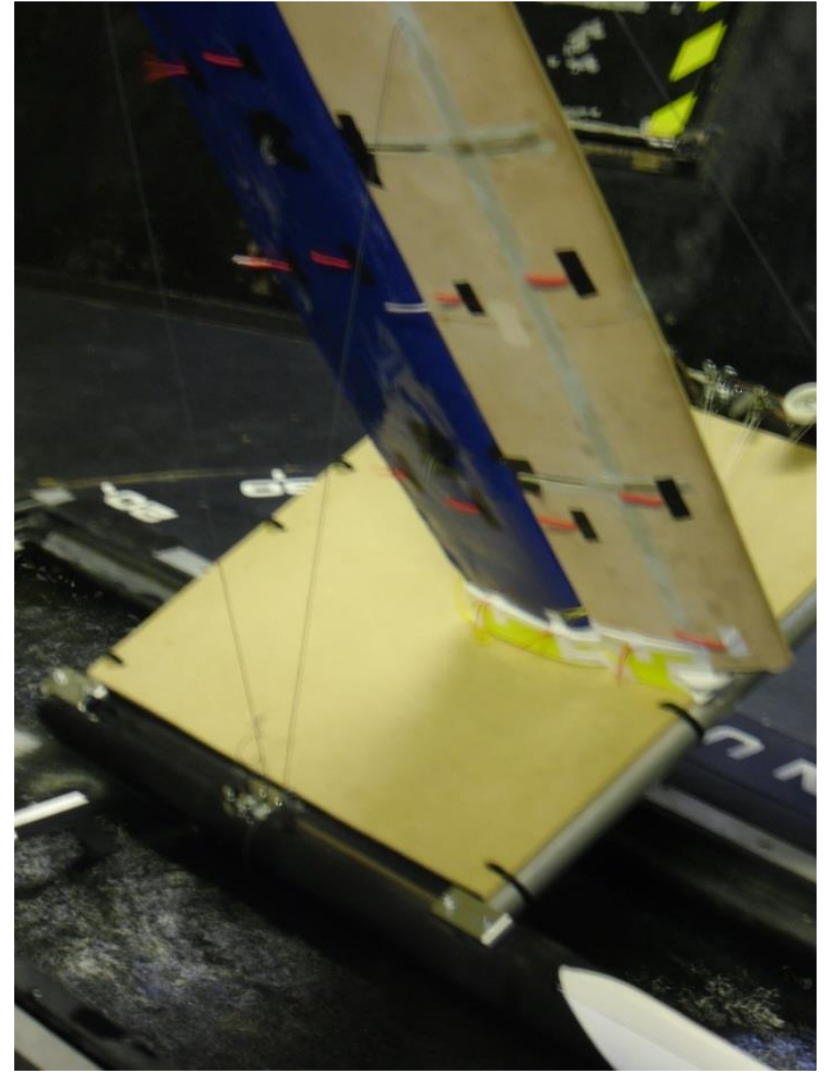

Figure 18: Wingsail foot depowered in sealed configuration

Moreover, the "sealed gap" wingsail presents a smaller base drag $\left(\mathrm{C}_{\mathrm{D} 0}=0.13\right)$, probably due to the shorter rig: the lower part of the wing is covered by the windward demihull resulting in less total windage drag.

\section{6}

\section{VPP WITH EXPERIMENTAL RESULTS}

\subsection{SCHERER VPP}

A VPP based on results from wind tunnel tests requires four values as a function of the AWA: $C_{\text {LMAX }}(\mathrm{Clx}), \mathrm{C}_{\mathrm{D}}$ (Cdt), CEh (Zce), and effective span (Span Eff).

The $C_{L} / \alpha$ plot from Scherer [10] shows that the wingsail is stalling at an AoA above 30-35 degrees. Nevertheless, wingsails can rotate on their base relative to the boat frame of reference, changing the overall angle of attack. The only limitation to this rotation is the position of the lateral shrouds. Therefore, the AWA at which the stall starts to occur does not coincide with the maximum AoA before stall. The apparent wind angle can be increased by easing the wingsail. In other words, by sheeting out the wingsail, the angle of attack is kept at the optimum value even if the AWA is increasing until the wingsail hit the lateral shrouds. An increase of 30 degrees $\left(\beta_{A}=60\right.$ degrees) is estimated to be reasonable. 
In the following table, the results for the double slotted wingsail from Scherer are tabulated. The internal values of Zce and Span Eff. used by the VPP for the initial run have been adopted. In reality, both centre of effort and effective heights will be different for the wingsail: the assumption is made in absence of this data from Scherer. As explained above, between 30 and 60 degrees, $C_{L}$ and $\mathrm{C}_{\mathrm{D}}$ are kept approximately constant because the wing will be eased in order to prevent stall.

Table 4: Scherer VPP experimental data

\begin{tabular}{|c|c|c|c|c|}
\hline $\boldsymbol{\beta}_{\mathbf{A}}$ & $\mathbf{C l x}$ & $\mathbf{C d t}$ & Zce & Span Eff \\
\hline 5 & 1 & 0.1 & 0.4866 & 1 \\
20 & 2.1 & 0.38 & 0.4866 & 1 \\
25 & 2.3 & 0.42 & 0.4866 & 1 \\
30 & 2.4 & 0.42 & 0.4866 & 1 \\
40 & 2.45 & 0.43 & 0.4866 & 1 \\
60 & 2.35 & 0.5 & 0.4866 & 1 \\
80 & $\underline{1.6}$ & $\underline{1}$ & 0.4866 & 1 \\
120 & $\underline{\underline{0.8}}$ & $\underline{2}$ & 0.4866 & 1 \\
180 & $\underline{\underline{0}}$ & $\underline{2.4}$ & 0.4866 & 1 \\
& & & & \\
\hline
\end{tabular}

The VPP fits a polynomial curve across the data points as presented in Figure 19: the solution algorithm starts to use the values of $\mathrm{C}_{\text {LMAX }}$; once the sail is generating too high heel force (i.e. $\mathrm{H}_{\mathrm{M}}>\mathrm{R}_{\mathrm{M}}$ ), a smaller $\mathrm{C}_{\mathrm{L}}$ of the polynomial fitting is used until the boat reach a steady state sailing condition (i.e. $H_{M}=R_{M}$ ).

In order to do that, the VPP needs values in the range of $\beta_{\mathrm{A}}=0$-180deg: the underlined values of Table 4 are considered reasonable values to cover the range of AWAs requested for the interpolation.

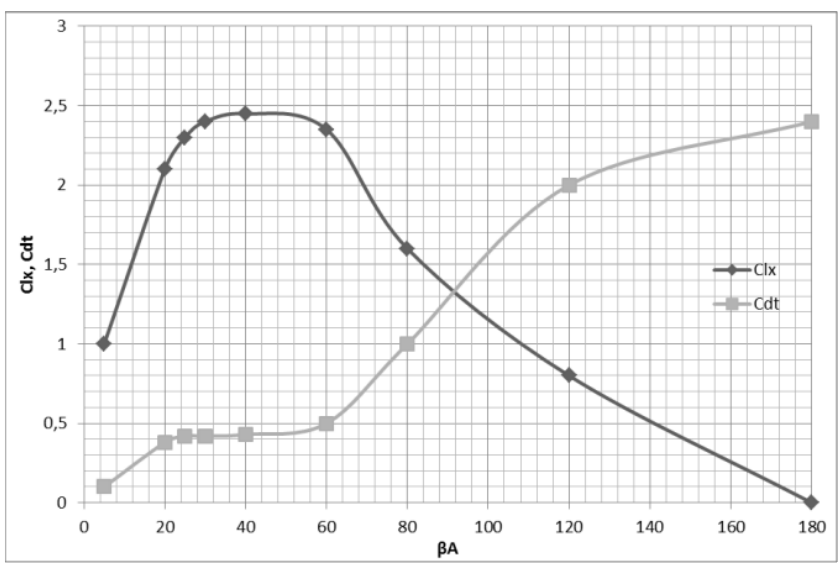

Figure 19: Scherer VPP polynomial fit

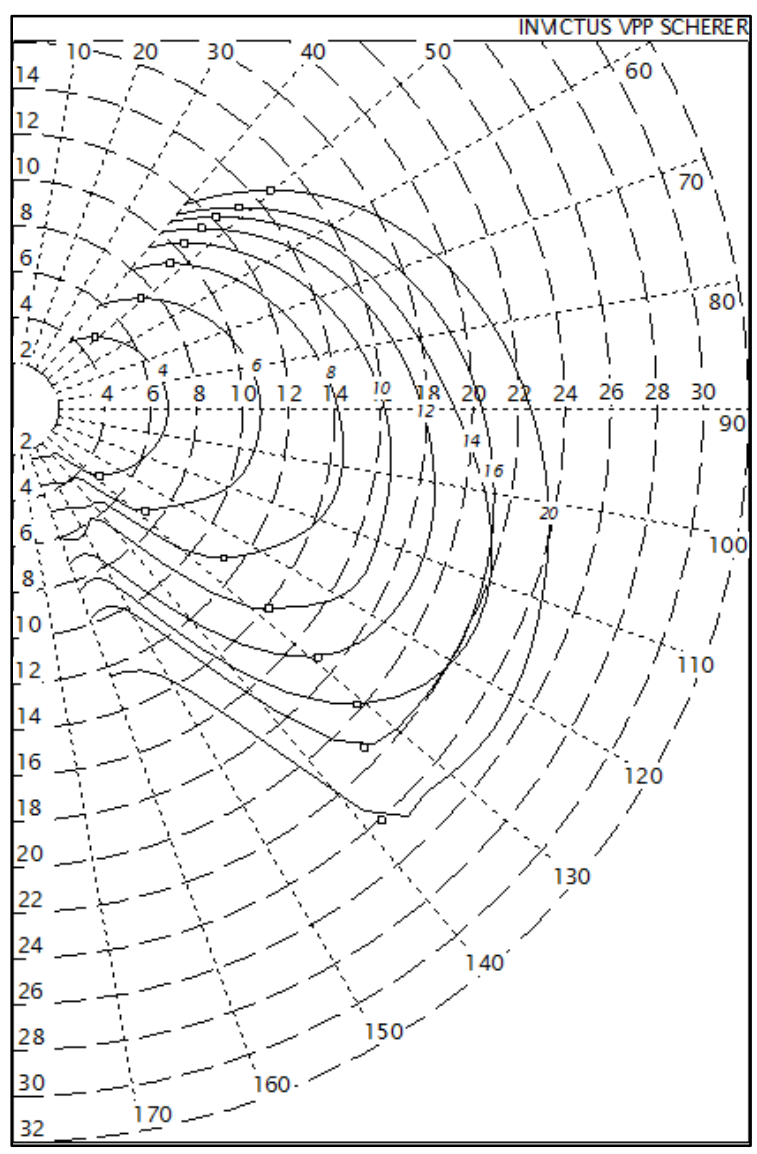

Figure 20: Scherer VPP

Windage components are associated with internal "shape function" in the VPP, which resolve the aerodynamic drag force into resistance and side force in yacht coordinate. Comparing "Scherer VPP" with the initial VPP setup (Figure 2), the former identifies faster performance for heavy winds (above 12 knots) when sailing off the wind. Considering that same values of flotation, CEh and Eff. Span. heights have been used, the reason for this behaviour is that the wingsail maximum $\mathrm{C}_{\mathrm{L}}$ is maintained constant for higher AWAs as was explained previously. For the double sail area VPP, above $\beta_{A}=25 \mathrm{deg}$, the sail starts to generate less lift whereas the drag keeps increasing. The mast, which is effectively the leading edge of the main, for higher AWAs produces more turbulence on the leeward side of the sail decreasing the lift generated [15].

\subsection{WIND TUNNEL VPP}

The results from the wind tunnel indicate that the wingsail used for the tests [5] does not achieve the high lift expected for a wing with a slotted flap. This is probably due to a poor manufactory over the slot opening between the elements. It was therefore necessary to "manipulate" the results in a sensible way in order to compare the velocity predictions with Scherer VPP.

Two different VPPs were run from the experimental results of the present research: a VPP with the wing at constant camber of 10-20 (respectively for upwind and 
for downwind) and the twisted configuration " $\mathrm{B}$ " in order to predict which value of $\mathrm{V}_{\mathrm{T}}$ marks the trade-off in performances between the constant cambered wingsail and the wing depowered at the tip.

For the constant cambered wing VPP, the following assumption was made: the $\mathrm{C}_{\mathrm{LMAX}}$ found by Scherer was used to calculate the values of $\mathrm{C}_{\mathrm{D}}$ by knowing the equation of the $C_{D} / C_{L}^{2}$ straight line from the tunnel experiments.

With values of $\mathrm{C}_{\mathrm{L}}$ and $\mathrm{C}_{\mathrm{D}}$ "scaled up" while maintaining the same $C_{D I}$ and $C_{D O}$ for the AWAs of 20, 25, 30 degrees, the assumption used for "Scherer VPP" (retarding the stall value of additional 30 degrees) is repeated. For the remaining AWAs the same typical values" for Scherer VPP are employed. The centre of effort heights and the effective span are the ones obtained in the tests. The following table represents the experimental data used in the VPP:

Table 5: Experimental data for wind tunnel VPP

\begin{tabular}{|ccccc|}
\hline $\boldsymbol{\beta}_{\mathbf{A}}$ & $\mathbf{C l x}$ & $\mathbf{C d t}$ & Zce & Span Eff \\
\hline 5 & 1 & 0.100 & 0.61 & 0.93 \\
20 & 2.1 & 0.396 & 0.54 & 0.93 \\
25 & 2.3 & 0.499 & 0.53 & 0.89 \\
30 & 2.4 & 0.540 & 0.51 & 0.88 \\
40 & 2.45 & 0.540 & 0.51 & 0.88 \\
60 & 2.35 & 0.580 & 0.51 & 0.88 \\
80 & $\underline{\underline{1.6}}$ & $\underline{\underline{1.000}}$ & 0.51 & 0.88 \\
120 & $\underline{\underline{0.8}}$ & $\underline{\underline{2.000}}$ & 0.51 & 0.88 \\
180 & $\underline{\underline{0}}$ & $\underline{\underline{2.400}}$ & 0.51 & 0.88 \\
\hline
\end{tabular}

The VPP results are presented in Figure 21 as a polar diagram. The overall predictions are not affected because the AWAs that result in best VMG downwind are all below $\beta_{A}=60 \mathrm{deg}$. Comparing the results with the "Scherer VPP the two different VPP configurations reach similar boat speeds $\mathrm{V}_{\mathrm{S}}$.

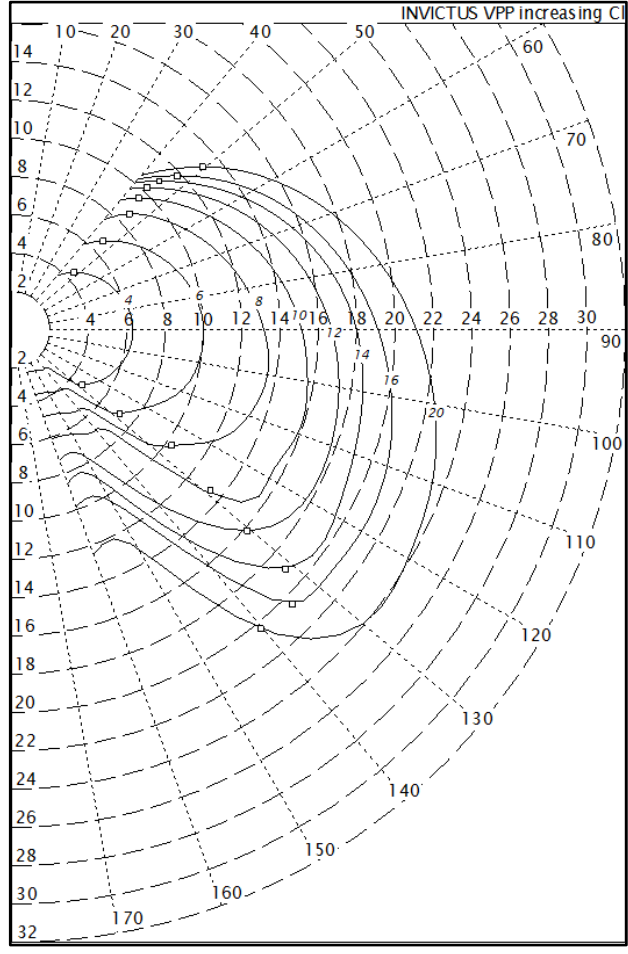

Figure 21: Wind tunnel VPP

It is considered that the "Scherer VPP" results are faster than the "constant cambered" wingsail for the following reasons. Firstly, the former $\mathrm{CEh}$, taken from the internal VPP values for a soft sail with same dimensions, is lower than the latter case; in terms of performances this results in the possibility of using a bigger percentage of the maximum thrust achievable without the need of flattening or twisting the wingsail. This is confirmed by comparing the tables of best flattening function for the optimum VMG of the two VPPs.

Table 6: Upwind best flattening for "wind tunnel VPP" and "Scherer VPP"

\begin{tabular}{|ccc|}
\hline $\mathbf{V}_{\mathbf{T}}[\mathbf{k n o t s}]$ & Constant camber & Scherer \\
\hline 4 & 1 & 1 \\
6 & 0,993 & 1 \\
8 & 0,877 & 0,936 \\
10 & 0,667 & 0,718 \\
12 & 0,535 & 0,577 \\
14 & 0,442 & 0,486 \\
16 & 0,374 & 0,413 \\
20 & 0,293 & 0,327 \\
\hline
\end{tabular}

"Scherer VPP" flattening function is higher for every wind speed: the $\mathrm{C}_{\text {LMAX }}$ is exploited better than the VPP using the tunnel data. Secondly, the induced drag measured in the tests is higher than the Scherer's wingsail, resulting in higher total drag generated by the 
wing which clarifies the reason for the bigger differences in $\mathrm{V}_{\mathrm{S}}$ in the upwind case.

For the twisted configuration "B", a different VPP has been set: the values of $C_{\text {LMAX }}, C_{D}$ using the equation of the straight line of $\mathrm{C}_{\mathrm{D}} / \mathrm{C}_{\mathrm{L}}^{2}$ are used. CEh and effective span have been calculated in the experimental tests.

The experimental values used in the VPP's run are:

Table 7: Experimental data used for "Twist B" VPP

\begin{tabular}{|ccccc|}
\hline $\boldsymbol{\beta}_{\mathbf{A}}$ & $\mathbf{C l x}$ & $\mathbf{C d t}$ & Zce & Span Eff \\
\hline 5 & 1 & 0.10 & 0.61 & 0.88 \\
20 & 2.1 & 0.43 & 0.46 & 0.88 \\
25 & 2.3 & 0.52 & 0.46 & 0.82 \\
30 & 2.4 & 0.58 & 0.43 & 0.85 \\
40 & 2.45 & 0.58 & 0.43 & 0.85 \\
60 & 2.35 & 0.61 & 0.43 & 0.85 \\
80 & $\underline{1.6}$ & $\underline{1.00}$ & 0.43 & 0.85 \\
120 & $\underline{\underline{0.8}}$ & $\underline{2.00}$ & 0.43 & 0.85 \\
180 & $\underline{\underline{0}}$ & $\underline{\underline{2.40}}$ & 0.43 & 0.85 \\
\hline
\end{tabular}

By estimating the race course of the LAC 2013 [3], it is possible to define at which $\mathrm{V}_{\mathrm{T}}$ the constant cambered wing has to be adjusted into the twisted configuration " $\mathrm{B}$ " to achieve better performances.

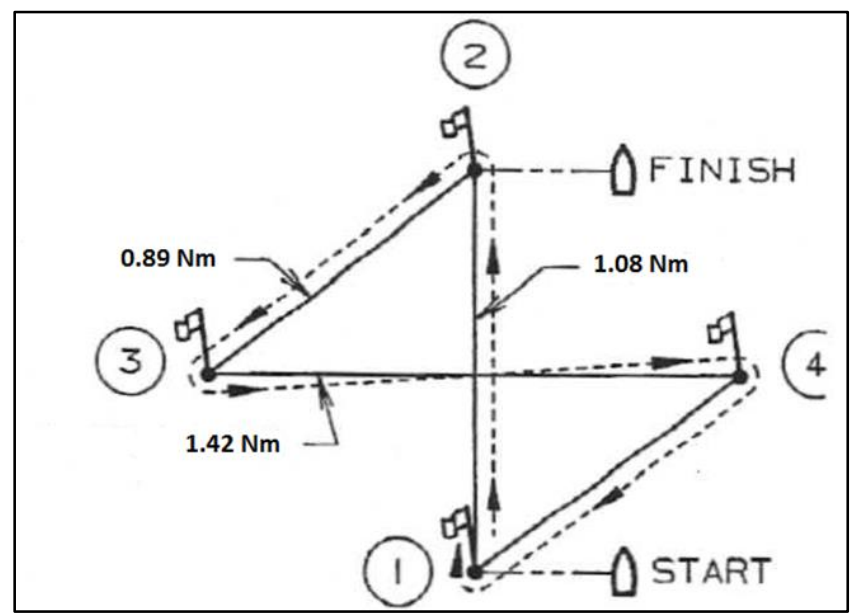

Figure 22: Sample Race track LAC 2013

The "constant cambered wingsail" and the twisted configuration " $\mathrm{B}$ " were sailed by the VPP along the new course of the LAC; the times in decimal minutes requested to finish the race for different $\mathrm{V}_{\mathrm{T}}$ are reported in Table 8.

Table 8: Minutes to complete one lap for "Constant Cambered" and "Twist B" wingsail

\begin{tabular}{|c|c|c|}
\hline $\begin{array}{c}\mathbf{V}_{\mathbf{T}} \\
\text { [knots] }\end{array}$ & $\begin{array}{c}\text { Constant camber [min } \\
\text { of race] }\end{array}$ & $\begin{array}{c}\text { Twist } \mathbf{B} \text { [min of } \\
\text { race] }\end{array}$ \\
\hline 4 & 137.3 & 142,0
\end{tabular}

\begin{tabular}{|c|c|c|}
6 & 88.6 & 91,7 \\
8 & 66.6 & 67,9 \\
10 & 55.2 & 54,7 \\
12 & 44.9 & 44,6 \\
14 & 41.1 & 39,0 \\
20 & 35.7 & 32,4 \\
\hline
\end{tabular}

From $\mathrm{V}_{\mathrm{T}}=10 \mathrm{knots}$ (medium wind speed) the twisted configuration starts to prevail against the constant cambered wingsail. Moreover, as the breeze increases, the advantage around the track of the twisted configuration is higher.

\section{CONCLUSIONS}

The flexible catamaran rig with adjustable twist wingsail proved a viable method of answering specific design questions relevant to wing sail based high performance yachts. Specific conculsions are as follows

(i) The heel angle reduces the performances of the catamaran, the optimum heel angle was found to be the flying angle (10 degrees) at which the windward demihull just sails clear of the water. Nevertheless, experiments have shown that downwind sailing is not affected by the heel angle to such a great extent as upwind.

(ii) The upwind experiments showed a decreased induced drag for lower heel angles. The gap underneath the wingsail influencing performance. The importance of the gap is more marked in the tests conducted at 30 degrees of heel: the trampoline with the solid platform resulted in smaller induced drag. In other words, by using a solid trampoline to maintain constant the gap underneath the wing foot, the performances at high heel angle increases.

(iii) The platform without the net was demonstrated to be the best option in terms of maximising drive force generated. The reason for this is the reduced drag of the trampoline. It is author's opinion that having a solid trampoline, able to generate a certain amount of lift in the direction of water, will produce righting moment useful in strong winds conditions. By adjusting the camber of the trampoline for light winds, lift can be generated to fly the windward hull. Nevertheless, the possibility of using a solid trampoline designed with an airfoil shape can be investigated in future research.

(iv) As found in the experiments and confirmed in the VPP analysis, a negative spanwise lift distribution at the tip of the wing is beneficial for upwind strong wind conditions.

(v) Sealing the gap underneath the wing foot did not improve the performances mainly due to the disturbed flow towards the wingsail's lower sections generated by 
the flying demihull. A visualization of the flow in wind tunnel (or CFD simulations) could have been beneficial to the understanding of the interaction and it should be motivation for future work in this area.

\section{REFERENCES}

1. Wellicome J. F., Some Comments on the Relative Merits of Various Wind Propulsion Devices. Journal of Wind Engineering and Industrial Aerodynamics, 20(1985) 11-142, Amsterdam.

2. Traut, T. et all, Propulsive power contribution of a kite and a Flettner rotor on selected shipping routes. Applied Energy 113, pp362-372, 2014

3. MacLane D.T., The Cogito project: design and development of an International C-Class Catamaran and her successful challenge to regain the Little America's Cup. The 13th Chesapeake Sailing Yacht Symposium, Annapolis, 2000.

4. Claughton, A. Wellicome, J., Shenoi, A., Sailing Yacht Design: Theory. Henry Ling Ltd, Dorset, 2006.

5. Scherer, J. Otto, Aerodynamics of high performance wing sails, SNAME CSYS, Annapolis, 1974.

6. Viola, I.M., et all, Upwind sail aerodynamics: A Rans numerical investigation validated with wind tunnel pressure measuraments. International Journal of Heat and Fluid Flow (2012).

7. Wood, C.J., Tan, S. H., Towards an optimum yacht sail. Journal of Fluid Mechanics, vol. 85, part 3, pp. 459-477, 1978.

8. Andrews, T. et all, Multihull America's Cup. Group Design Project: University of Southampton, Southampton, 2011.

9. YET Lecture Notes, MSc in "Yacht and Small Craft": University of Southampton, 2011.

10. Campbell, I.M.C., Optimization of a sailing rig using wind tunnel data. SNAME 13th Chesapeake Sailing Yacht Symposium, Annapolis, 1997.

11. Campbell, I.M.C., The performances of offwind sails obtained from wind tunnel tests. R.I.N.A. International Conference on modern Yacht, London, 1998.

12. Campbell, I.M.C., Claughton A.R., Wind tunnel testing of sailing yacht rigs. 13th HISVA symposium, Amsterdam, 1994.

13. Jackson, P.S., Modelling the aerodynamics of upwind sails. Journal of Wind Engineering and Industrial Aerodynamics 63, 1996.
14. Campbell, I.M.C., A comparison of downwind sail coefficients from tests in different wind tunnels. Innov'Sail, Lorient, 2013.

15. Gentry, A., Studies of Mast Section Aerodynamics. In: Proceedings of the 7th AIAA Symposium on the Aero/Hydronautics of Sailing, Long Beach, California, 1976. 